\title{
Quantitative changes in protein, glycogen and fat content in the eggs of the locusts, Locusta migratoria migratorioides and Schistocerca gregaria (Orthoptera), during embryogenesis
}

\author{
VÁCLAV NĚMEC \\ Institute of Entomology, Czech Academy of Sciences, Branišovská 31, České Budějovice, 370 05, Czech Republic; e-mail: \\ nemec@entu.cas.cz
}

Key words. Embryogenesis, protein, glycogen, neutral lipids, sterols, Locusta migratoria, Schistocerca gregaria

\begin{abstract}
Changes in the content of protein, glycogen, neutral lipids and sterols were investigated in locust eggs from oviposition until larval hatching. The content of all of these nutritional reserves was higher in the eggs of $S$. gregaria because of their larger size, although relative changes in utilization or synthesis of these materials during embryogenesis showed a more or less parallel course. The amount of protein increased progressively during embryogenesis, while glycogen and neutral lipids were successively metabolized or utilized for development of the embryo. There appeared significant relative differences in the way of utilizing energetic reserves during embryogenesis between the two species. This was especially manifested by a larger relative decrease in the content of neutral lipids (mainly triglyceride) in the eggs of $S$. gregaria. Conversely, the eggs of $L$. migratoria showed a larger relative utilization of glycogen reserves. The content of steroids was higher in the eggs of $S$. gregaria during the initial 6 days of embryonic development. Later on, during advanced stages of pharate larval development, the steroids were rapidly utilized and decreased in both species. The described changes in utilization of the main energetic resources were correlated with periods of tissue growth and differentiation and with the cuticulogenesis of the growing embryo.
\end{abstract}

\section{INTRODUCTION}

Insect eggs represent a self-sustaining system which provides the raw materials for building the larval body and the energy reserves to cover all of the energy demands during embryogenesis (Sander et al., 1985). The development of the embryo is dependent upon the appropriate physiological and environmental conditions. The most important environmental condition for development of the embryo is favourable temperature and humidity (Hamilton, 1950).

It is known that lipid and carbohydrate reserves decrease as embryogenesis progresses. The carbohydrate metabolism in the eggs of the grasshopper Aulocara ellioti has been described by Quickenden (1970). The changes in lipid content and function have been surveyed in various insect species by Gilbert (1967). The aim of this study is to compare the parallel changes in protein, glycogen and lipid content in the eggs of L. migratoria and $S$. gregaria during embryogenesis.

\section{MATERIAL AND METHODS}

The eggs of migratory locusts, Locusta migratoria migratorioides (R. et L.) and Schistocerca gregaria (Forsk.) were used in the assay. These eggs were collected every day from our stock culture to have the samples of a known time of incubation. The eggs were incubated in wet sand at a temperature $32-35^{\circ} \mathrm{C}$. They eclosed between day 11-13, eggs were sampled up to day 10.

\section{The sampling methods}

Each egg was homogenized in 70\% methanol using an allglass pestle homogenizer. The homogenate was transferred into a glass centrifuging tube and centrifuged at 4000 r.p.m. $/ 10 \mathrm{~min}$. The supernatant was poured into another tube and an equal volume of petroleum ether was added to the supernatant and to the sediment. Then the samples were shaken vigorously, the sediment was centrifuged again, and the combined petroleum ether extracts were poured into thin-wall tubes and left to evaporate in digestory under room temperature. The dried residues were used for determination of neutral lipids using vanillin reagent according to Zoelner and Kirsch (1962). The results are given in equivalents of oleic acid.

Then the sediment was extracted again with methanol, centrifuged, and the combined methanol extracts were left to evaporate in a fumehoud at the room temperature. The dry remnants were dissolved in glacial acetic acid and used for determination of sterols according to method of Zlatkis et al. (1953). The results are expressed in cholesterol equivalents.

The sediment was used for determination of proteins and glycogen: The sediment was hydrolysed in $1 \mathrm{~N} \mathrm{NaOH}$ overnight at room temperature. Half of the hydrolyzate was used for direct determination of protein content using biuret reagent according to Goa (1953). The results were then calculated into bovine serum albumin equivalents. The other half was used for determination of glycogen using the method of Good et al. (1933) for isolation of glycogen and phenol - sulphuric acid reagent according to Dubois et al. (1956) for colorimetric determination. The results were calculated in glucose equivalents.

The data were statistically evaluated. The cummulative data represent the average and standard deviations of analyses in 15 eggs.

\section{RESULTS}

\section{Changes in protein content}

The quantity of proteins in the eggs of $S$. gregaria revealed no significant changes during embryogenesis. A slow increase of protein content was seen in the eggs of L. migratoria (Fig.1). Thus the rate of change of protein content could reflect the fact that the eggs of $S$. gregaria are bigger and heavier than that of L. migratoria. 

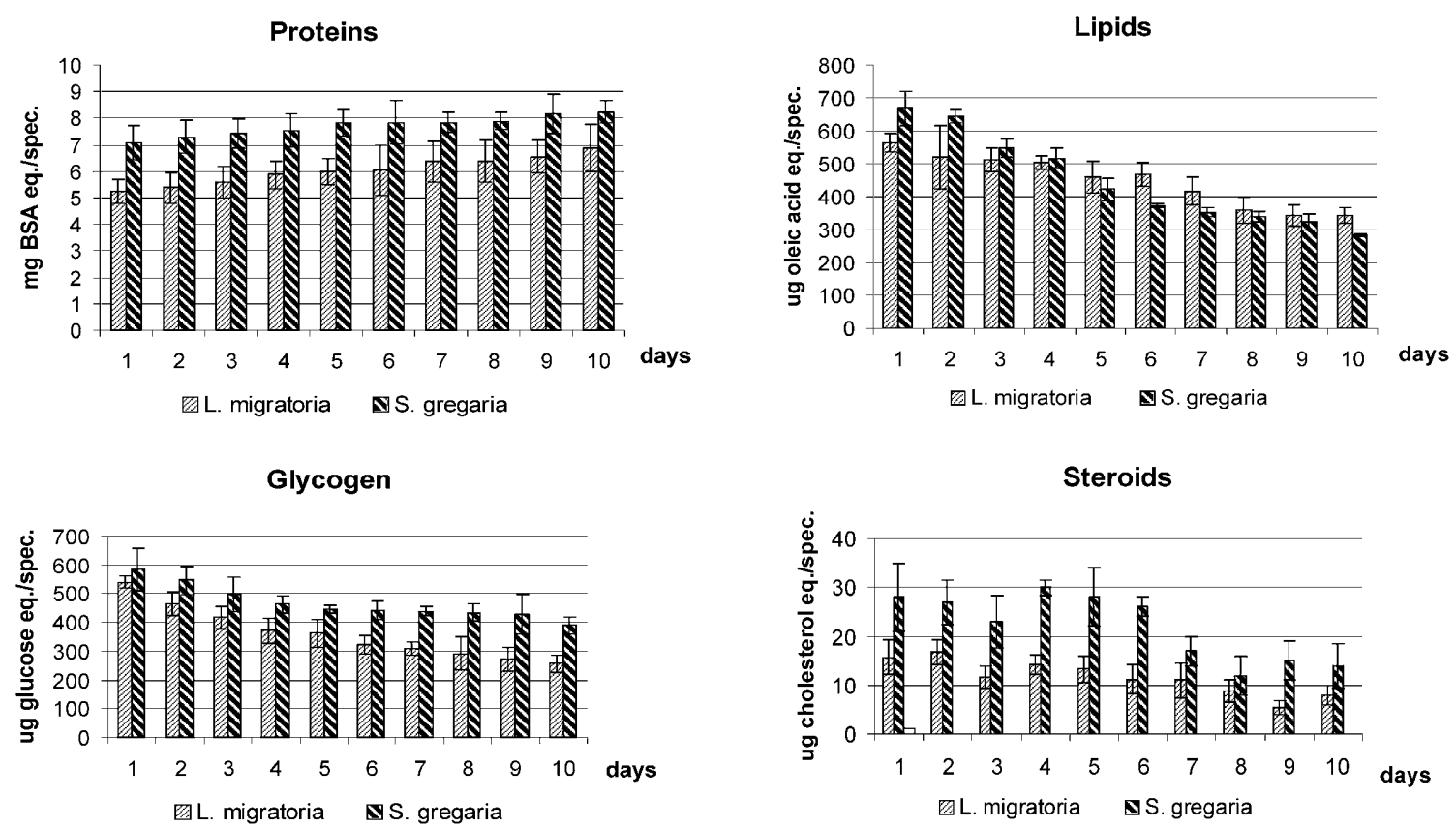

Figs 1-4. 1 - changes of protein content (in mg of bovine serum-albumin equivalents) in the eggs of Locusta migratoria and Schistocerca gregaria during embryogenesis; 2 - changes of lipid content (in $\mu \mathrm{g}$ of oleic acid equivalents) in the eggs of $L$. migratoria and $S$. gregaria during embryogenesis; 3 - changes of glycogen content (in $\mu \mathrm{g}$ of glucose equivalents) in the eggs of $S$. gregaria and L. migratoria during embryogenesis; 4 - changes of steroid content (in $\mu \mathrm{g}$ of cholesterol equivalents) in the eggs of $L$. migratoria and $S$. gregaria during embryogenesis. (Means, $\overline{\mathrm{x}} \pm$ s.d.; $\mathrm{n}=15$ ).

\section{Changes in glycogen content}

The amount of glycogen decreased during embryogenesis, particularly in the eggs of L. migratoria (by $52 \%$ when compared with the glycogen content in the freshly laid eggs). The decrease of glycogen content in the eggs of $S$. gregaria is not so obvious (only about $33 \%$ ) during the entire embryogenesis (Fig. 3).

\section{Changes in lipid content}

The content of lipids in the eggs of both locust species steadily decreased during embryogenesis, particularly in the eggs of $S$. gregaria (Fig. 2). When the changes in lipid content (in triglyceride) at the beginning and at the end of embryogenesis were compared, it was found to decrease by $39 \%$ in the eggs of L. migratoria, and by $58 \%$ in S. gregaria. It is evident that triglyceride is the main source of energy for all processes during embryogenesis.

\section{Changes in steroid content}

The steroid content in the eggs of two locust species differs greatly (Fig. 4). The eggs of $S$. gregaria have a two-fold higher content of steroids than those of $L$. migratoria during the six days of incubation. After the day seven the content of steroids in the eggs of $S$. gregaria decreased rapidly. The content of cholesterol in the eggs of L. migratoria also decreased, but not so rapidly as in $S$. gregaria. The decrease of steroid content in the eggs of both species at day 3 is probably connected with katatrepsis. The decrease at the end of embryogenesis is probably due to the synthesis of larval cuticle.

\section{DISCUSSION}

Locusts have probably one of the largest eggs of all insects. The development of the locust embryo lasted about 11-13 days in wet sand at a temperature $30-32^{\circ} \mathrm{C}$. Because of the relatively slow development they are the ideal model for study of insect embryogenesis. This has been demonstrated in the studies of
Roonwal (1936, 1937) performed on the African migratory locust, Locusta migratoria migratorioides. He confirmed the older data of Slifer (1932) who described the daily growth changes in the developing embryo of the grasshopper, Melanoplus differentialis. Later the study of Hamilton (1950) described the dependence of the rate of development on temperature and humidity in the eggs of $L . m$. migratorioides and Schistocerca gregaria.

The above mentioned authors followed the daily change in embryo growth. Shulov \& Pener (1959) declared this method of study of embryogenesis inappropriate. They described in their detailed study dealing with the developing embryo of L.migratoria at least 23 developmental stages which lasted about 16 days at $27^{\circ} \mathrm{C}$. However, the development of Locusta eggs in our stock culture was shorter, due to the higher temperature, as mentioned above. Along with the description of developmental stages they also estimated the daily changes in weight and water content in the locust eggs.

The eggs of $S$. gregaria differ from those of L. migratoria in several respects: they are bigger and heavier. The protein content in L. migratoria eggs during embryogenesis varied between 74 and $84 \%$ of that in S. gregaria (Fig. 1).

Differences between the eggs of S. gregaria and L. migratoria were also found in the rate of utilization the glycogen reserves. While the decrease in glycogen content in $S$. gregaria eggs was not so remarkable, in L. migratoria it was significantly greater (Fig. 3). It seems that glycogen in the eggs of L. migratoria serves to a larger extent as a source of energy. This fact was indirectly confirmed by estimation of the changes in lipid content during embryogenesis in both S. gregaria and L. migratoria eggs (Fig. 2). The data shows that lipids are utilized more extensively in the eggs of $S$. gregaria than in the eggs of $L$. migratoria

The content of glycogen was found to be relatively low (see Fig. 3). It is in agreement with the data of Quickenden (1970) obtained by analysis of eggs of the grasshopper, Aulocara 
ellioti. Most of glycogen was spent at the end of embryogenesis. The above mentioned author also estimated increased level of free sugars as embryogenesis progressed. The dominant free sugar was trehalose, which documents mobilization of the glycogen reserves.

Additional confirmation of our data are the results of Boell (1935) and recently Sláma (2000) who screened the respiration of the eggs of $S$. gregaria. Sláma discovered that the respiratory quotient of the eggs is 0.7 . It is evident that the main source of energy for all metabolic processes during embryogenesis are lipids, particularly triglycerides. Our data on lipid utilization also corresponds with the results of Allais et al. (1964) obtained with the eggs of L. migratoria and Lipsitz and McFarlane (1970) with the eggs of house cricket, Acheta domesticus. Allais et al (1964) found that the content of triglycerids decreased in the eggs of $L$. migratoria during embryogenesis by $52 \%$, which corresponds with our data.

The content of sterols as was estimated varied between $2.2-3.4 \%$ of the total fat content. It is again in good agreement with the data of Allais et al. (1964) on the eggs of L. migratoria and with the data of Svoboda et al. (1966) with the eggs of Aulocara ellioti. They found that the dominant steroid is cholesterol (about $95 \%$ of all steroid content). According to the submitted results, the changes in steroid content probably reflected the processes of cuticulogenesis at the stage of katatrepsis and at the end of embryogenesis when the larval cuticle was synthesized (Fig. 4).

The size of eggs and nutrient content are influenced by various factors. McIntyre \& Gooding (2000) found that egg size, egg content, hatch rate and biochemical characteristics in the eggs of Musca domestica correlated with the age and size of $M$. domestica female. Proteins, carbohydrates and lipids are transported from fat body to the eggs during oogenesis in the form of glycolipoproteins (vitellogenins) as was documented earlier (Chinzei et al., 1981; for survey see also Kunkel \& Nordin, 1985).

ACKNOWLEDGEMENTS. This study was supported by grant No. 522/98/0773 provided by Czech Grant Agency. Author also thanks to I. Řezníčková for technical assistance and J. Kovalovský for preparation of figures.

\section{REFERENCES}

Allais J.P., Bergerard J., Etienne J. \& Polonovski J. 1964 Nature et évolution des lipides au cours de 1' embryogenèse de Locusta migratoria migratorioides (R.et L.). J. Insect Physiol. 10: 753-772.

BoELL E.J. 1935: Respiratory quotients during embryonic development. J. Cell Comp. Physiol. 6: 369-385.

Chinzer Y., Chino H. \& Wyatt G.R. 1981: Purification and properties of vitellogenin and vitellin from Locusta migratoria. Insect Biochem. 11: 1-7.

Dubors M., Giles K.A., Hamilton J.K., Rebers P.A. \& Smith F. 1956: Colorimetric method for determination of sugars and related substances. Analyt. Chem. 28: 350-356.

GILBERT L.I. 1967: Lipid metabolism and function in insects. Adv. Insect Physiol. 4: 69-211.
GoA J. 1953: A microbiuret method for protein determination. Scand. J. Clin. Lab. Invest. 5: 218-222.

Good C.A., KRAMER H. \& Somogy M. 1933: The determination of glycogen. J. Biol. Chem. 100: 485-491.

HAMILTON A.G. 1950: Further studies on the relation of humidity and temperature to the development of two species of African locusts, Locusta migratoria migratorioides (R. et F.) and Schistocerca gregaria (Forsk.). Trans. R. Entomol. Soc. Lond. 101: 1-58.

KUNKEL J.G. \& NoRDIN J.H. 1985: Yolk proteins. In: G.A. Kerkut \& L.I. Gilbert (eds.): Comprehensive Insect Physiology, Biochemistry and Pharmacology, Vol. I., Pergamon Press, Oxford, pp. 83-111.

Lipsitz E.Y. \& McFarlane J.E. 1970: Total lipid and phospholipid during the life cycle of the house cricket, Acheta domesticus (L.). Comp. Biochem. Physiol. 34: 699-705.

McIntrre G.S. \& Gooding R.H. 2000: Egg size, content and quantity: maternal age and size effects on housefly eggs. Canad. J. Zool. 78: 1544-1551.

Quickenden K.L. 1970: Carbohydrates in eggs of the grasshopper, Aulocara ellioti during development. J. Insect Physiol. 16: $171-183$.

Roonwal M.L. 1936: Studies on embryology of the African migratory locust, Locusta migratoria migratorioides (R.et F.). I. Early development with a new theory of multi-phased gastrulation among insects. Phil. Trans. (B) 226: 391-421.

Roonwal M.L. 1937: Studies on embryology of the African migratory locust, Locusta migratoria migratorioides (R. et F.) (Orthoptera: Acrididae). II. Organogeny. Phil. Trans. 227: 175-244.

SANDer K., Gutzeit H.O. \& Jackle H. 1985: Insect embryogenesis: morphology, physiology, genetical and molecular aspects. In: Kerkut G.A. \& Gilbert L.I. (eds): Comprehensive Insect Physiology, Biochemistry and Pharmacology, Vol. I, Pergamon Press, Oxford, pp. 319-386.

SLÁMA K. 2000: Correlation between metabolic depression and ecdysteroid peak during embryogenesis of desert locust, Schistocerca gregaria (Forsk.) (Orthoptera: Acrididae). Eur. J. Entomol. 97: 141-148.

Shulov A. \& PENER M.P. 1959: A contribution to knowledge of the development of the egg of Locusta migratoria migratorioides (R. et F.). Locusta (Paris) 6: 73-88.

SLIFER E.H. 1932: Insect development. IV. External morphologyof grasshopper embryos of known age and with a known temperature history. J. Morphol. 53: 1-21.

Svoboda J.A., Pepper J.H. \& BaKer G.I. 1966: On the lipid of the egg of grasshopper, Aulocara ellioti. J. Insect Physiol. 10: 753-772.

Zlatkis A., ZaK B. \& Boyle A.J. 1953: A new method for the direct determination of serum cholesterol. J. Lab. Clin. Med. 41: 486-492.

Zoelner N. \& Kirsch K. 1962: Über die quantitative Bestimmung von Lipoide (Mikrometode) mittels der vielen natürlichen Lipoiden (allen bekanten Plasmolipoiden) gemeisamen Sulfo- Phospho-Vanillinen Reaktion. Z. Ges. Exp. Med. 135: 545-561.

Received July 3, 2001; revised November 7, 2001; accepted February 6, 2002 